\title{
VENCIENDO A PROCUSTO. EL CONCEPTO DE FAMILIA: EL FEMINISMO LIBERAL, EL POST-FEMINISMO Y EL PROBLEMA DEL GÉNERO
}

\author{
Nicolás Ried Soto* \\ Universidad de Chile, Chile \\ nicolasried@hotmail.com
}

\begin{abstract}
RESUMEN: En relación con el Derecho, la perspectiva de género se ha estructurado como una potente crítica a algunas instituciones fundamentales. La institución familiar, una de las menos cuestionadas, es la que presenta mayores flancos a partir de los cuales se puede construir la revolución social desde lo sexual, o sea, una verdadera revolución sexual. Dicha transformación ha sido articulada por una parte, con las críticas provenientes desde el feminismo liberal. Postura que evidencian las fallas internas del actual entendimiento jurídico acerca de lo sexual y lo familiar; y por otra parte, la crítica extra-sistémica realizada desde el post-feminismo cuyo discurso resalta la imposibilidad del sostenimiento de lógicas esencializadoras y universalizantes de la vida en sociedad.
\end{abstract}

Palabras clave: feminismo, Michel Foucault, Teoría queer, familia.

ABSTRACT: In relation to the law, the gender perspective has been a potent tool for criticizing certain fundamental institutions. The institution of the family, one of the least questioned, is that which presents the most opportunities for constructing a social revolution from a sexual revolution, a true sexual revolution. On the one hand, criticisms stemming from the same liberal logic, such as that of liberal feminism, evidence the same internal defects as the current legal understanding regarding the sexual and the familial. On the other hand, extra-systemic, post-feminist criticism evidences the impossibility of sustaining essential and universal logic of life in society.

Keywords: feminism, Michel Foucault, Queer theory, family.

Estudiante de Licenciatura en Ciencias Jurídicas y Sociales de la Facultad de Derecho de la Universidad de Chile, sexto semestre. Ayudante ad honorem de las cátedras de Filosofía Moral, Teoría Social e Introducción a la Filosofía de la Ciencia. 


\section{LA “CAMA DE PROCUSTO”}

El concepto de familia existente en Chile puede ser entendido de mejor manera tras la invocación del mito de Procusto. Procusto ofrecía una cama de hierro a los viajeros, a fin de que reposaran del cansancio que los acometía, sin embargo, cuando la cama le quedaba corta al caminante, el anfitrión se encargaba de cortarle las extremidades sobrantes; a su vez, cuando la cama quedaba larga, estiraba al yaciente, moliendo sus huesos, hasta que ocupara la cama en todo su largo. De la misma manera que los huéspedes de Procusto, el problema de la familia radica en que dicha institución, en relación con sus integrantes, presenta un espectro de aceptabilidad muy acotado, no obstante ser aquel que permite el reconocimiento de las relaciones interpersonales entre los sujetos, dentro de la sociedad civil y en relación con el Estado.

La familia, como concepto jurídico no definido legalmente de modo general, tiene la pretensión de explicar la realidad de las formas en que los sujetos establecen relaciones sociales, amorosas, patrimoniales, filiales y conductuales, espectros que nuestro sistema jurídico reduce a la procreación. Al existir tantas formas de vida como personas, deben ser todas respetadas como legítimas valorativamente, por ello el concepto que defina este tipo de relaciones debe ser lo más amplio posible en cuanto a elementos potenciales de su realización, siendo esa amplitud el precio de mantención de un concepto unitario y sistemáticamente coherente. Por eso cuando se presenta un concepto de familia restringido a la realización previa de un matrimonio heterosexual, se deja de lado arbitrariamente un número importante de formas de vida que existen en la realidad social, tal como Procusto cercenaba los miembros de aquel que quedaba largo en la cama; por otra parte, el concepto de familia no debe ser absolutamente amplio, de modo tal que cualquier tipo de relación quepa en él, ya que ello determinaría su vaguedad e imprecisión explicativa, estirando cualquier relación a ser caracterizada como familiar, lo que destruiría la utilidad que podría presentar este elemento en el sistema jurídico tal como Procusto destruía los huesos de quien quedaba corto en la cama.

La idea de "ajustar a la fuerza" que nos presenta el relato, se presenta de manera analógica en la relación que se suscita entre las prácticas sociales (sobre las cuales se construyen las costumbres y, mediatamente, la moral) y la regulación normativa de las conductas de los sujetos. Tal relación de "ajuste" se presenta además en términos discursivos, cuando no hay coherencia al rechazar conclusiones que se seguirían tomando como base los valores y principios sobre los cuales se funda la lógica que pone en movimiento el contexto en que lo sujetos se desarrollan, a saber, los del liberalismo.

Nuestro sistema, en tanto lógica sobre la cual los sujetos establecen juicios valorativos sobre determinadas prácticas y se desarrollan conductualmente, tiene un origen y una caracterización actual liberal. Los conceptos de libertad e igualdad, en términos liberales, están en concreta armonía y unión; sin embargo, ocurre que ante un análisis gramaticalmente profundo de tal liberalismo, las nociones superficiales caen. 
Para realizar una crítica al concepto de familia vigente en nuestro sistema jurídico, presentaré los argumentos utilizados por dos ramas del feminismo, una integrante de este movimiento político y teórico, y otra reaccionaria ante éste. Me refiero al feminismo liberal y al postfeminismo. La primera respuesta será desde el feminismo liberal originado en el siglo XIX, cuyo paradigmático expositor es John Stuart Mill, para lo cual utilizaré los argumentos de éste a fin de entregar una mirada proveniente del utilitarismo, como posición liberal y particularmente como una crítica intra-sistémica de la posición de no dar una definición del concepto familia. Una segunda crítica estará dirigida desde el post-feminismo, particularmente desde la teoría queer, de la mano de los argumentos de Michel Foucault y Judith Butler, esta vez desde una posición externa al liberalismo, permitiendo reconocer errores fundamentales de división sexual de los sujetos y, por lo tanto, de la constitución de una institución como la familia. El conjunto de estas críticas tiene la pretensión de poner en evidencia la imposibilidad del liberalismo de dar cabida ni al más cercano de los feminismos ni, mucho menos, al más lejano de ellos, ante la pregunta básica por quiénes son los sujetos (y en qué medida lo son) que forman parte de la sociedad.

Por otra parte, el Derecho, en general, y la institución de la familia, en particular, son instituciones sociales de normalización: es en la familia el lugar de la biografía del sujeto donde podemos discernir si es normal o anormal. Por ello, es relevante darle a las críticas mencionadas un enfoque específico, de búsqueda de las posibilidades sobre las cuales el sujeto pueda ser libre, en cuanto no regido por los criterios de normalidad impuestos sobre él.

\section{EL FEMINISMO LIBERAL}

El origen del movimiento feminista es situado tradicionalmente en un tiempo paralelo a la Revolución Francesa, con el particular hecho de la Declaración de los Derechos de la Mujer y la Ciudadana promovida por Olympe de Gouges (1791). La extensión de la proclama de libertad, igualdad y fraternidad debía abarcar a todo el género humano, sin exclusión de la mitad de la humanidad, vista desde una perspectiva sexual.

El movimiento feminista, luego, se extendió hacia el resto de Europa. Al año siguiente de la publicación en Francia, en Inglaterra es publicada la Vindicación de los Derechos de las Mujeres de la pluma de Mary Wollstonecraft, texto inspirador de lo que sería el sufragismo, o sea, el movimiento que apoyaba la idea de la extensión del derecho a sufragio de las mujeres.

Dos hechos importantes marcarán el devenir del pensamiento feminista a lo largo del siglo XIX, y constituirán aquello que entenderemos como feminismo liberal. En un ambiente político en que se discute la participación femenina y su derecho a sufragio, la Declaración de Seneca Falls en 1848 da forma a un discurso no sistematizado de denuncia de una situación 
de desigualdad; el segundo hecho - que será en el que nos detendremos en esta sección - es la publicación de The subjection of women (desde aquí simplemente tratada según su traducción como La sujeción de las mujeres ${ }^{1}$ ) por John Stuart Mill en 1869.

La relevancia histórica de la publicación de La sujeción se da en consideración del debate sobre la sexualidad, las instituciones constituyentes de los sujetos (la educación, la familia, el matrimonio, entre otras) y principalmente el rol de los sujetos en la sociedad en la sociedad victoriana inglesa del diecinueve. Sobre este último punto, son destacables dos grandes "ideólogos" de la naturalización de los sujetos, en términos que deben cumplir con determinadas labores y conductas, a fin de ser "moralmente correctos"; me refiero a Ruskin y Smiles, dos autores participantes de la discusión victoriana sobre el rol de la mujer. La argumentación de estos autores giraba en torno a la existencia de un mandato divino y natural que definía con claridad las funciones y deberes sociales de mujeres y hombres, a la existencia de una sociedad naturalmente binaria, al mandato de adscripción de los sujetos a un ámbito público (siendo hombre) o a uno privado (siendo mujer) y a la idea de la inferioridad femenina ${ }^{2}$.

En definitiva, la tesis sobre la cual Mill estaba en posición de contraargumentar era la de una existencia natural de la división y jerarquización de los sexos, estando el sexo femenino subordinado al masculino. Los argumentos de esta tesis patriarcal, a modo de síntesis, son ${ }^{3}$ : primero, el temor a que la participación política de las mujeres derivara en un atentado en contra de la familia, entendida como la institución transmisora de los valores esenciales de la sociedad; la inferioridad mental y física de las mujeres, en términos tales que no es equiparable la participación de una mujer con la de un hombre; y en tercer lugar, la inutilidad del voto femenino, por estar éstas sobre-representadas por sus padres y maridos, además de contar con diversas protecciones legales. Esos argumentos son los que creaban el grupo conservador de argumentos a favor de la naturaleza femenina y mantenimiento del status quo.

Los argumentos de Mill, siguiendo a Ana de Miguel $^{4}$, pueden ser agrupados en dos categorías: los primeros son una directa contraargumentación a la idea de naturaleza diferente y complementaria de los sexos, y los segundos son el sustento teórico del feminismo como mecanismo de progreso de la humanidad.

1 Mill, John Stuart. "La sujeción de las mujeres". En su: Mill, John Stuart y TaYlor Mill, Harriet. Ensayos sobre la igualdad sexual. Valencia, España: Ediciones Cátedra, Universitat de Valencia, 2001.

2 Caviglia, María Jorgelina. “Discurso y naturaleza femenina: ideología sexista en la Inglaterra victoriana”. En: Actas del III coloquio nacional de investigadores en estudios del discurso. Buenos Aires, Argentina, 2006, p. 3.

3 Caviglia, María J. y Marinsalta, Claudia I. Debates victorianos por la ciudadanía y la participación politica femenina (Inglaterra, siglo XIX), 2008.

4 De Miguel, Ana. El feminismo en clave utilitarista ilustrada: John S. Mill y Harriet Taylor Mill. En: Amorós, Celia y De Miguel, Ana (eds.). Teoría feminista: de la ilustración a la globalización. Madrid, Espańa: Ediciones Minerva, 2005, pp. 177 209. 
Dentro del primer grupo ubicamos los siguientes argumentos, expuestos por Mill en $L a$ sujeción: primero, el argumento del agnosticismo, el que indica que nada se puede saber respecto de la naturaleza humana mientras las ciencias etológicas no lo permitan, así que al no existir conocimiento posible sobre la naturaleza humana, con menores razones se puede argumentar la existencia de una naturaleza femenina.

En segundo lugar, el argumento empírico, el cual dice relación con una tríada de conceptos que Mill expone en Utilitarism: voluntad-deseo-hábito. La distinción que realiza entre la voluntad o querer (will) y el deseo (desire) ${ }^{5}$ reconoce a la voluntad como un fenómeno activo, en oposición al carácter pasivo del deseo, dándole además a la voluntad una relación de dependencia con el deseo, de modo que la voluntad sin un deseo previo no existiría. Existiría, sin embargo, una posibilidad de independencia de la voluntad: "La voluntad, al igual que otros aspectos de nuestra personalidad, es modelada por el hábito, de forma que podamos querer a causa del hábito lo que ya no deseamos por sí mismo, o que solamente deseamos porque lo queremos (will) [...] La voluntad es hija del deseo, y abandona el dominio de su progenitor sólo para pasar a depender del hábito" 6 .

En esta relación deseo-voluntad, Mill incorpora al hábito como elemento deformador de la dependencia, en términos tales que además de querer lo que deseamos, podemos querer aquello a lo que estamos habituados. Expone así Mill la contingencia de la argumentación victoriana sobre la complementariedad de los sexos, diciendo de ella que la subordinación femenina está siendo así simplemente porque siempre ha sido así, sin mayor fundamento.

En tercer lugar, el argumento de la universalización de la condición humana se presenta en el contexto sistemático de una argumentación basada en los principios milleanos del utilitarismo como postura ética. El principio de utilidad, planteado por Mill, consiste en la mayor felicidad para el mayor número de personas, definiendo felicidad como "el placer y la ausencia de dolor"7. Lo relevante en Mill, es que cada individuo, independiente de su sexo, suma uno al cómputo final de felicidad, ya que es premisa que tanto hombres como mujeres tienen derecho a la felicidad.

Y ante esto, me quedo con la interpretación que Urmson hace del utilitarismo de Mill como un utilitarismo de reglas ${ }^{8}$, en oposición a un utilitarismo de actos: el principio de utilidad no opera caeteris paribus frente a un acto de un agente moral, sino que evalúa todos los factores determinantes en el caso, lo que incluye la existencia de una regla moral; así, por ejemplo, si el acto de matar a otro fuera útil en una circunstancia determinada, no debe obviarse que con

\footnotetext{
Mill, John Stuart. El utilitarismo. Madrid, España: Alianza editorial, 2007, pp. 102 - 104. 
ello se está diciendo además que la regla de matar a otro es menos útil que matar a ese otro, teniendo en consideración la dimensión performativa del lenguaje. Se exige del agente moral que opere de acuerdo al principio de utilidad, teniendo en cuenta la totalidad de factores que influyen al hecho y que se cuestione si realizar un acto determinado es más útil que mantener la regla moral contraria, toda vez que una agencia moral determinada niega la regla de conducta moral contraria: cuando mato a otro estoy diciendo que es más útil que mantener la regla moral de no matar a otro.

La argumentación de Mill está enfocada a convencer de sus argumentos a un espectro muy amplio de lectores, participando en la discusión política victoriana y principalmente en la discusión legislativa sobre el voto femenino ${ }^{9}$. Sus argumentos son diversos en ese sentido, pero su objetivo teórico es poner en el mercado de la competencia utilitaria sus argumentos con los contrarios, lo que se explica desde sus ideas expuestas en On liberty sobre otra tríada relevante en la obra de MILL: verdades-opiniones-utilidad. La pretensión de verdad que sustenta la emisión de opiniones es la que permite entender que en este mismo acto existe una potencia de utilidad: lo verdadero es lo idealmente útil, sin embargo, aquello verdadero no es alcanzable (como tampoco lo es la naturaleza humana) por lo que sólo pueden obtenerse opiniones superiores a otras, que mediante la emisión y el contraste se miden según el principio de utilidad. Así, la misma existencia de variadas opiniones es útil, en tanto la depuración que se produce de esas ideas permite acercarse a lo verdadero, ya que la determinación de utilidad de una postura es opinable y por tanto destruible con otra opinión. Este argumento valida la protección de la libertad de expresión, valorando la existencia de muchas opiniones, pero restringiendo al mismo tiempo la calidad de las opiniones a mensajes no portadores de verdad, sino de pretensión de verdad destruible por otra que tenga base de argumentos más sólidos: "ante hechos y argumentos, ceden opiniones y costumbres erróneas" 10 , siendo cierto que "la verdad de una opinión forma parte de su utilidad"11.

La división de las capacidades de los sujetos en relación con sus sexos tiene como base una idea de naturaleza humana. Sobre la naturaleza humana no podemos conocer lo verdadero, pero sí podemos opinar en relación a ello. Así, la división sexual se basa en una opinión, y las opiniones no deben estar consagradas en el sistema jurídico al no contener en sí condición de verdad: "Las preferencias y aversiones de una determinada sociedad, o de una parte influyente de la misma, son las que, de manera principal y en la práctica, han determinado aquellas normas que, bajo amenaza de sanción por la ley y la opinión, han de ser observadas por todos"12.

\footnotetext{
9 Mill fue elegido parlamentario de la Cámara de los Comunes en 1865 y en 1866 presentó la primera petición de voto para las mujeres.

10 Mill, John Stuart. Sobre la libertad. Madrid, España: EDAF, 2007, p. 72.

11 Ibid., p. 76.

12 Ibid., p. 48.
} 
Las normas de conducta son determinadas en base a criterios obtenidos de la discusión de opiniones y no de una determinada "verdad" revelada al legislador. En ese sentido chocan las opiniones y obtienen su mérito en relación con la utilidad comparativa que prestan. Sobre ese sentido, estructurar un sistema normativo de conductas en base a la división y jerarquización sexual no es adecuado, ya que - y esta es la tesis de Mill - un estado de igualdad de los sexos reporta mayor utilidad:

"A la larga, el valor de un Estado es el valor de los individuos que lo componen, y un Estado que deje de lado los intereses de desarrollo y perfeccionamiento mentales de sus ciudadanos, a cambio de una agilidad administrativa un poco mayor en la forma de llevar cada asunto o de la mera apariencia de la misma que le confiere la rutina; un Estado que empequeñezca a sus hombres, con el fin de convertirlos en instrumentos más dóciles en sus manos, aun con fines beneficiosos, se encontrará con que con hombres pequeños no puede realizarse ninguna cosa realmente grande; y que la perfección de la maquinaria a la que ha sacrificado todo, al final, no le valdrá para nada, por falta de esa energía vital que ha preferido proscribir, en aras de un mejor funcionamiento del mecanismo engrasado"13.

De esta manera, el rol de Mill como pensador utilitarista, lo lleva a la conclusión de un proto-feminismo funcional, en términos que está enmarcado en una serie de consecuencias jurídicas que se siguen de la persecución de la mayor felicidad para el mayor número de personas.

Es entonces como Mill debe construir sobre esta tesis la utilidad extra que reporta la igualdad de los sexos. Para ello, la argumentación en La sujeción continúa estableciendo una fuerte relación entre la felicidad que reporta la utilidad, con la libertad producida por la igualdad entre los sujetos. Así, la secuencia igualdad-libertad-utilidad-felicidad tiene su elemento inicial en un quinto concepto, el cual es fundamento del pensamiento liberal inglés y del pensamiento ilustrado en general: el progreso. Es la idea de progreso la que permite a Mill responder la posible crítica práctica a su idea de igualdad de los sexos sobre la felicidad particular de los sujetos que desean seguir cumpliendo sus patriarcales roles de hombre y mujer. La respuesta ante la felicidad particular por el hábito en un sistema de desigualdades es que el progreso de la humanidad es un bien superior y máximo en términos utilitarios, que permitiría el desarrollo de la humanidad como tal, llevando a todos los sujetos que la integren a un estado superior. En definitiva, la humanidad ha llegado hasta donde está gracias al esfuerzo público de la mitad de la humanidad, diría el argumento patriarcal; Mill diría que podríamos avanzar el doble si la mitad inactiva, las mujeres, tuvieran las mismas capacidades sociales que los hombres.

Bajo el supuesto de que Mill debe argumentar en un entorno sumamente patriarcal, las ideas sobre las que construye el concepto de progreso mediante la adopción de un feminismo liberal, tienen como elementos constructores del discurso, una serie de elementos patriarcales

13 Ibid., p. 249. 
que se asumen como existentes. Esos argumentos y elementos los revisaremos a continuación: el primero de ellos es el que considera que la familia es una escuela de igualdad; el segundo sobre la competencia instrumental de la humanidad; y el tercero y más criticado, el argumento de "la compañera”.

El primer argumento considera que la igualdad de los sexos debe ser educada desde la socialización primaria, es decir, desde el núcleo fundamental del sujeto que constituye la familia. Esta adopción de la educación como motor de la construcción moral de los sujetos es bastante similar a la concepción que la sociedad victoriana tiene respecto de dicha institución, ya que si la familia es el motor educativo de la moral de los sujetos, asume que la procreación es un elemento necesario de la familia, lo cual asociado a la idea de matrimonio como condición necesaria de la familia, es cuestionable en términos liberales, por motivos que revisaremos en las secciones siguientes. Además, fuera del trauma sufrido por John Stuart Mill debido a la educación totalitaria que le dio su padre (James Mill) y su padrino (Jeremy Bentham), la educación es un tema principal para su proyecto teórico: si toda la comunidad está educada bajo el principio de utilidad, se pueden esperar conductas morales racionales, de lo contrario, se da cabida a la existencia de free riders.

En segundo lugar, el argumento de la competencia instrumental que adquirirían los sujetos dada la igualdad sexual, se funda en una primacía del rol masculino, ya que la idea de progreso que hasta aquí ha tenido la humanidad se debería al desarrollo llevado a cabo por los hombres, precisamente porque el argumento muestra que si las mujeres fueran como los hombres, la humanidad ya habría avanzado el doble de lo que ha avanzado hasta ahora. En este caso Mill asume la jerarquización de los sexos como una constatación, aunque se considera que este es meramente retórico, debido a las pretensiones prácticas de convicción del proyecto milleano.

El último argumento y más criticable es el que dice que a los hombres debiera serles grato tener un par que los acompañe en su vida, alguien que fuera como ellos en definitiva. El argumento de "la compañera" señala lo beneficioso que sería para los hombres que las mujeres fueran como ellos, argumento de suyo criticable por los mismo contraargumentos que no logra responder el feminismo de la igualdad: qué sentido tiene luchar por la igualdad cuando el parámetro de igualación es el masculino, sentido sobre el cual sólo la mitad de la población tendrá que modificarse para ser como la otra.

Así se conforma el feminismo liberal, fundado en los preceptos liberales del utilitarismo y enmarcado en el espectro de los feminismos de la igualdad. Ahora, bajo una revisión crítica del sistema jurídico chileno, cabe elucidar las incongruencias de un sistema jurídico que presume ser liberal, pero resultar ser sistemáticamente patriarcal. Desde aquí la idea de la cama de Procusto se hace cada vez más clara. 


\section{CRÍTICA AL CONCEPTO DE FAMILIA DESDE EL FEMINISMO LIBERAL}

"La familia es el núcleo fundamental de la sociedad"14 se escribe en la Carta Fundamental de la República chilena, lo que nos lleva a estimar la importancia que el Estado de Chile le entrega a este concepto. Un concepto consagrado como núcleo fundamental de la sociedad en el cuerpo legal de mayor importancia reviste a esta institución de un de halo de poder; y por otra parte nos remite a pensar en que, al poseer tal relevancia, debe tener un estatuto especial que la proteja y le entregue los alcances que merece. Sin embargo, el concepto de familia, tras una breve revisión a la legislación, parece estar vacío.

Si revisamos los diferentes cuerpos legales que se encuentran vigentes en Chile nos llevaremos una gran sorpresa, pues en ninguno de ellos se encuentra contenida ninguna definición ni siquiera aproximativa del concepto de familia. Lo único que podemos mencionar para estos efectos es el Pacto Internacional de Derechos Civiles y Politicos de 1976 suscrito por Chile y que dice: "La familia es el elemento natural y fundamental de la sociedad y tiene derecho a la protección de la sociedad y del Estado. Se reconoce el derecho del hombre y de la mujer a contraer matrimonio y a fundar una familia si tienen edad para ello" 15.

Además, esta descripción está anexada en una ley nacional, a saber la ley de matrimonio civil, que establece esta misma relación casi causal entre familia y matrimonio: "La familia es el núcleo fundamental de la sociedad. El matrimonio es la base principal de la familia"16.

Al ser esta la aproximación al concepto vigente de familia que, legalmente, impera en Chile y que ni siquiera es una definición del concepto, podemos evidenciar la primera característica social que la sociedad patriarcal pretende mantener: la unión matrimonial heterosexual.

Al mencionar que la familia es la institución social de mayor importancia, nos lleva a darles la misma o mayor importancia a sus fundadores, los cuales son y deben ser un hombre y una mujer. Esta es una declaración abierta de discriminación invisibilizadora en contra de cualquier otro tipo de familia distinto del que propugnan los defensores de la sociedad patriarcal.

El juego retórico presente en la relación familia/matrimonio es el de, si bien no igualar, asociar de manera dependiente y necesaria la constitución de una familia sólo a través del matrimonio, y así asociar la estabilidad de la sociedad toda a la estabilidad de la institución matrimonial. La pregunta es cuál es la finalidad de proteger la institución matrimonial, al nivel de entregarle el rango indirecto de fundadora de la sociedad.

\footnotetext{
14 República de Chile. Constitución Politica de la República de Chile. Art. 1, inciso segundo. Santiago, Chile: Editorial Jurídica de Chile, 2010.

15 Pacto Internacional sobre Derechos Civiles y Políticos. Art. 23, incisos primero y segundo. 1976.

16 República de Chile. Ley de matrimonio civil (ley No 19.947). Art. 1, inciso primero. 2004.
} 
El matrimonio en Chile está consagrado en el Código Civil y se define como un contrato: "El matrimonio es un contrato solemne por el cual un hombre y una mujer se unen actual e indisolublemente, y por toda la vida, con el fin de vivir juntos, de procrear y de auxiliarse mutuamente" 17 .

Cabe preguntarse por cuáles son los argumentos que sostienen que el matrimonio deba ser entre un hombre y una mujer, con exclusión de cualquier otra combinación de sexos. Dichos argumentos rondan alrededor de que los virtuales matrimonios que no fueran heterosexuales, a contrario sensu, serían matrimonios homosexuales.

Si analizamos la finalidad del matrimonio impuesta por la ley -que por cierto excluye cualquier finalidad que no sea funcionalista, como por ejemplo el amor entre dos personas- podemos distinguir tres fines específicos: vivir juntos, procrear y auxiliarse mutuamente. Se podrá entender que una pareja de homosexuales o de lesbianas puede cumplir sin mayores problemas los requisitos de vivir juntos y auxiliarse mutuamente; sin embargo, los defensores de la sociedad patriarcal tienen el argumento de que una pareja de homosexuales o lesbianas no puede procrear y con eso termina la discusión, al menos desde su punto de vista. Lamentablemente para ellos, existen contra-argumentos ante esa posición: si permitimos a una pareja heterosexual estar unidos en matrimonio por el mero hecho de que tienen la capacidad de procrear, debiera estarle prohibido casarse a parejas estériles, parejas cuya edad les impida procrear, parejas que no tengan intención alguna de procrear, o sea prohibirle a todo tipo de parejas que no puedan/ quieran cumplir con esta finalidad social, e incluso debiera solicitarse como requisito extra para consumar el matrimonio que la pareja engendre un hijo o una hija, dejando así de lado también a las parejas que tengan la idea de adoptar un hijo o hija en vez de procrear.

Entonces, si no es la finalidad social la que obliga a mantener la estructura heterosexual del matrimonio ¿cuál es la finalidad de hacerlo? Propongo que es sostener el sistema de dominación del hombre por sobre la mujer, el sistema patriarcal y consecuentemente el estado de las cosas.

El escenario del Derecho en general es desfavorable para la mujer, más aún el escenario del Derecho enmarcado en las relaciones matrimoniales. No es mi intención enumerar las notablemente discriminatorias regulaciones relacionadas a los temas matrimoniales, que cuenta incluso con doctrina que la sustenta "teóricamente"18.

Es en el sistema familiar basado en el matrimonio donde el hombre tiene todas las prerrogativas que le permiten estar sobre la mujer y someter a esta a las labores meramente domésticas. Aquí, con la institución familiar se establece la dicotomía público/privado, en que

17 República de Chile, op cit. (n. 16). Art. 102.

18 Cf. Fries, Lorena y Matus, Verónica. El derecho. Trama y conjura patriarcal. Santiago, Chile: LOM ediciones, 1999. 
el mundo público le corresponde al hombre y el mundo privado a la mujer; y en cuanto entendemos que la necesidad del matrimonio a fin de establecer una familia es innecesario, podemos entender que esta dicotomía no tiene fundamento alguno.

Es a través del matrimonio como se logra delimitar la esfera de libertad de los individuos, pues esta a su vez limita la concepción de familia y por lo tanto la de sociedad, convirtiendo en un atentado en contra de toda la sociedad cualquiera opinión diferente que se tenga de las uniones familiares. Se invisibiliza además a los sujetos que no estén adscritos a la institución familiar: hijos fuera del matrimonio, hijos no reconocidos, homosexuales, lesbianas, parejas que conviven, grupos de personas que no poseen vínculos sanguíneos, etcétera.

El problema se presenta desde su base conceptual, en que el legislador no entrega una definición clara de familia y se remite a asociar su significado a la institución matrimonial, asegurando a esta última con la construcción de la sociedad que a todos nos engloba. Así, ante el silencio de la ley, la definición de familia queda en manos del poder judicial basándose en parámetros arbitrarios e incluso poco serios. Consideremos que los parámetros que utilizan para definir en sus sentencias el concepto de familia son los siguientes: "La palabra familia, de acuerdo con el artículo 20 del Código Civil, según el Diccionario de la Real Academia Española, significa conjunto de personas unidas por el vínculo del matrimonio y del parentesco" ${ }^{19}$. Se utiliza así una definición cargada axiológicamente por una de las instituciones más defensoras de la sociedad patriarcal, como es la Real Academia de la Lengua Española.

Produciéndose este silencio, la definición queda al arbitrio de los jueces, y son estos en último término los que realizan la labor de asociar necesariamente los conceptos de matrimoniofamilia-sociedad. Es por ello que considero que una forma de desatar este nudo de conceptos es a través de una definición de familia que contemple los cambios que la sociedad experimenta en su totalidad y que además sea extensa y abierta a fin de aceptar nuevos procesos sociológicos no contemplados al momento de definir. Además, como forma de asegurar esta definición es necesario que posea rango constitucional, y que en el fondo todos los ciudadanos sean los que constituyan el núcleo fundamental de la sociedad.

Al entregarse una definición constitucional de familia que se libre de su relación de dependencia con el matrimonio heterosexual, se abre la posibilidad de formar una multiplicidad de distintos tipos de familia que, si bien existen hoy en nuestra sociedad, no son reconocidos por la legislación chilena. Además al entregar una definición de familia que sea independiente del matrimonio, se deconstruye la situación de dependencia entre la estabilidad matrimonial y la estabilidad social.

19 Corte Suprema de Chile. Luque Arias, Miriam con Bobadilla Cartagena, Nelson. Rol Ingreso Corte No 2800-03, del 31 de mayo de 2004. 
Como he mencionado, el concepto de familia que se incorpore a nuestras bases de la institucionalidad pasará a convertirse en una institución de Derecho más, que como todas ellas, regulará la conducta de los individuos. Será necesario que abarque la mayor cantidad de sujetos y grupos de individuos, y que a su vez no se fundamente en relaciones de carácter meramente sanguíneo, sino que sea acompańado por el concepto psicológico de la misma. Es por ello que propongo lo siguiente, tomando como fundamento la libertad utilitarista del feminismo liberal: Se entenderá por familia: dos o más personas que guardan relaciones de parentesco por consanguinidad; dos o más persona que, sin guardar relaciones de parentesco por consanguinidad, guardan relaciones de parentesco por filiación; dos o más personas que conviven y se prestan auxilio mutuo; o, finalmente, dos o más personas que manifiestan su voluntad de constituirse como familia.

Esta concepción de la institución familiar abre la posibilidad de establecer relaciones sociales institucionalizadas, de modo tal que la libertad particularmente considerada de los sujetos aumente en términos utilitaristas. Primero, se mantienen las posibilidades actuales de estructuración familiar, lo cual previene de antemano las contra argumentaciones dirigidas contra una posible "destrucción" del concepto y la institución familiar, como sí ocurre ante la negativa de un "matrimonio gay" en Chile, puesto que no impide que las cosas sigan como hasta ahora, sólo aumenta las posibilidades de conjugación de la posición de los sujetos en su ámbito familiar. En segundo término, abre la posibilidad a que los sujetos no estén determinados desde su nacimiento a cargar con determinadas consideraciones sociales e incluso emocionales en relación con los integrantes de su familia, esto cuando consideramos que podría presentarse ante los tribunales la existencia de una "familia de hecho", sin consideración de un acto volitivo previo, como hoy es el matrimonio. Y en tercer lugar, deja de lado consideraciones sobre las prácticas sexuales de los sujetos, elemento que hasta hoy es fundamental para que se considere que alguien deviene familia con otro, como revisamos supra.

Si bien, el concepto de familia propuesto no sería aceptado por la opinión liberal tradicional, lo presento como un concepto coherente y sistemático con la libertad de los sujetos de constituirse como miembros de la sociedad. El liberalismo tradicional defiende la libertad de elección, en la que se puede elegir estar dentro de la sociedad o no, formar una familia o no. Lo que no se puede elegir es precisamente la forma en que se quiere participar dentro de la sociedad, pues esta está ya predispuesta: no podemos elegir qué tipo de familia llevar, y que esta sea reconocida como tal, las instituciones están ya definidas.

\section{POST-FEMINISMO}

Uno de los clásicos del cine queer, Glen or Glenda?, proponía el tema de la (no) diversidad sexual análogo a la siguiente opinión: "Érase una vez, no hace mucho tiempo, cuando el mundo decía: ‘ ¿aviones? ¡Eso va en contra de la voluntad del Creador! Si el Creador hubiese 
querido que voláramos nos habría dado alas" ${ }^{20}$. El protagonismo de aquel filme era el travestismo, el cual además de competir por el reconocimiento como una posibilidad digna dentro de las mecánicas de aceptación moral en nuestra sociedad, debe competir como una forma de sexualidad autónoma y distinta de la homosexualidad.

Lo anterior es útil para comprender la lucha que emprenden los movimientos feministas radicales y el post-feminismo, sobre todo considerando su alianza estratégica con los movimientos de reivindicación de las "minorías sexuales" (homosexuales, lesbianas, transgénero, travestis, intergénero, etc.) y "minorías raciales" (principalmente de color de piel y étnicas), como también con posturas éticas naturalistas (caso ejemplar el movimiento ecofeminista o de feminismo cyborg). Dentro de la división del Feminismo, podemos encontrar aquellos feminismos que velan por la igualdad entre hombres y mujeres, como también aquellos feminismos que conservan la diferencia entre hombres y mujeres. Las categorías de análisis de los feminismos que presentaré, se basa en el trabajo de Samara de las Heras ${ }^{21}$.

Los primeros, los feminismos de la igualdad problematizan la posición de las mujeres, de modo tal que muestran la existencia de una división sexual y una posterior jerarquización de los sexos, en que los símbolos sociales masculinos se encuentran valorados por encima de los femeninos. Entre estos feminismos ubicamos al feminismo liberal, al feminismo marxista y al feminismo socialista.

Los segundos, los feminismos de la diferencia, se ocupan de valorar el hecho de que existe una diferencia entre hombres y mujeres que no puede ser obviada. Promueven valorar las características de lo que se constituye como femenino en paralelo con los elementos masculinos e incluso la destrucción del paradigma masculino. Las feministas de la diferencia acusan que el feminismo de la igualdad promueve la equiparación a un estándar masculino, o sea, a la masculinización de lo femenino. Entre estos feminismos ubicamos al feminismo radical, al feminismo con base psicológica y al feminismo cultural.

Fuera de estos feminismos ubicamos una corriente fundada en el estudio de la filosofía contemporánea y de los desarrollos interdisciplinarios de los estudios de género provenientes del post-estructuralismo y en general desde la post-modernidad. Este feminismo que ha sido denominado post-moderno, da una respuesta a ambos feminismos mencionados antes, puesto que establece la idea fundante de que estas doctrinas feministas no se cuestionan la existencia de una identidad denominada "mujer": las unas equiparan el paradigma "mujer" con el paradigma "hombre", las otras esencializan a la mitad de la población en un concepto general y universalizante denominado "mujer" (u "hombre").

20 Véase el film de Wood, Ed. Glen or Glenda? de 1953.

21 De las Heras, Samara. "Una aproximación a las teorías feministas", en: Universitas. Revista de Filosofía, Derecho y Política, No 9, enero 2009, pp. 45 - 82. Madrid, España: Instituto de Derecho Humanos "Bartolomé de Las Casas", Universidad Carlos III de Madrid. 
En el sentido anterior, el feminismo post-moderno no sería un feminismo, bajo el entendimiento tradicional, pues como tal no tiene como objetivo luchar por la reivindicación de la posición de lo femenino en nuestra sociedad, sino que lucha precisamente por destruir aquello que denominamos de manera maniqueísta "mujer"/"hombre".

La cuestión sobre la familia radicaría, por lo tanto, en la necesidad de consideración del género a fin de establecer las vinculaciones sociales generales sobre las cuales el lenguaje jurídico podrá referirse a un conjunto de sujetos como familia. Así, es necesario identificar cómo nuestro sistema jurídico declara a alguien "hombre" o "mujer". En esos términos, podemos anticipar que los elementos sobre los cuales se declara que un sujeto tenga un determinado sexo son exteriores, pues el argumento es científico: si tiene pene es hombre, si tiene vagina es mujer ${ }^{22}$. Socialmente, podemos "ver actitudes" masculinas y femeninas, sobre las cuales definir si alguien es hombre o mujer (vestimenta, modo de hablar, forma de moverse, etc.). Incluso, el discurso jurídico reconoce que un sujeto puede ser considerado de un sexo o de otro según sus prácticas sexuales (si practica relaciones sexuales con un hombre cuando la ciencia dice que es "mujer", es mujer para la ley; si practica el sexo con una mujer debiendo ser "hombre", es hombre; si practica el sexo con un hombre debiendo ser un hombre, queda fuera del circuito aceptado, pasando a ser homosexual; fuera de esta categoría quedan las lesbianas, puesto que al no existir penetración en sus prácticas sexuales, no hay tal, lo que evidencia una carga patriarcal incluso dentro de las mecánicas de las sexualidades excluidas $)^{23}$.

Todas las posibilidades de determinación del sexo anteriormente presentadas, tienen pretensión de objetividad, sin embargo su técnica universalizante paga el precio de reducir todas las posibles formas de vida que los sujetos pueden tener a sólo una: la heterosexualidad como norma. Con lo anterior, podemos evidenciar que nuestro sistema jurídico tiene un fuerte compromiso teórico con esta forma de mirar la sexualidad, de entender la sexualidad como un conjunto de prácticas que se dan de modo necesario en el conjunto de sujetos que componen la sociedad.

El post-feminismo entiende, siguiendo a Michel Foucault, que el poder es una situación estratégica y no una cosa que permanece en instituciones como el Estado solamente. Como situación estratégica presente en todas las ramas de la sociedad, debe combatirse desde una perspectiva de libertad que abarque todo el espectro social del sujeto particular. En ese sentido, puede entenderse que la sociedad está desde ya masculinizada, y feminizarla no sería una salida que acabara con el problema: la cuestión es de raíz. Por ello, es necesario pensar de modo distinto, dejar de lado el binarismo y entender que no es posible reprochar moralmente ni coaccionar

22 Maffia, Diana y Cabral, Mauro. "Los sexos ¿son o se hacen?”. En su: Sexualidades migrantes. Género y transgénero. Buenos Aires, Argentina: Editorial Feminaria, 2003, pp. 86 - 96.

23 Mackinnon, Catharine. "Sexualidad”. En su: Hacia una teoría feminista del Estado. Valencia, España: Ediciones Cátedra, Universitat de Valencia, 1989, pp. $127-154$. 
jurídicamente a los sujetos por no seguir el estándar normativo de comportamiento sexual. Una respuesta a este problema fundamental, el de la división sexual, lo da la llamada queer theory, cuya representante principal es Judith Butler.

Judith Butler, señaló muy precisamente en una entrevista qué es lo queer: "Para mí, ser queer es una expresión que desea que uno no tenga que presentar una tarjeta de identidad antes de ingresar a una reunión. Los heterosexuales pueden unirse al movimiento queer; los bisexuales pueden unirse al movimiento queer. Ser queer no es ser lesbiana; ser queer no es ser gay. Es un argumento en contra de la especificidad lesbiana. Que si soy lesbiana tengo que desear de cierta forma o si soy gay tengo que desear de cierta forma. Queer es un argumento en contra de cierta normativa, de lo que constituiría una adecuada identidad lesbiana o gay" 24 .

El post-feminismo, desde la teoría queer, se sale de los márgenes de estudio que contempla el feminismo, tanto de la igualdad como de la diferencia, ya que problematiza un presupuesto básico y asumido por el análisis del sometimiento femenino desde Olympe de Gouges: el status de "lo femenino". Así, el post-feminismo considera que el estatus de "hombre" o "mujer", no problematizado por el feminismo clásico, merece ser revisado, pues ahora el agente de opresión de los sujetos no es el "hombre", sino la categoría misma de género. El llamado "giro copernicano" de Butler adquiere importancia cuando la idea de destrucción del género es una cuestión de reformulación de los sujetos del programa político feminista y social en general, pero particularmente en relación con el discurso jurídico: "El problema del 'sujeto' es fundamental para la política, y concretamente para la política feminista, porque los sujetos jurídicos siempre se construyen mediante ciertas prácticas excluyentes que, una vez determinada la estructura jurídica de la política, no 'se perciben'”25.

Siguiendo a Carol Smart, el discurso jurídico tiene sexo, pero más importante aún, tiene la capacidad de producir el género de los sujetos que regula. El proyecto feminista problematizó el uso lingüístico "Mujer" para referir de una vez a todo el sexo femenino, pues como concepto es universalizante al categorizar la totalidad de sujetos que cumplan con una serie de elementos biológicos adscritos a su cuerpo, dándoles un set de características descriptivas/prescriptivas de cómo la mujer "es"/"debe ser". La solución, en este sentido, del proyecto feminista es la utilización del ruido "mujeres", pues daría cabida a una idea identitaria entre los sujetos entendidos como mujer, como a su vez reconoce la diferencia entre los distintos sujetos que están bajo esa categoría. Sin embargo, este giro lingüístico no da una solución final, sino que incluso retorna sobre el mismo punto de creación discursiva de los sujetos: "La Mujer no es, simplemente, un

24 Michalik, Regina. "La invención de la palabra", entrevista realizada a Judith Butler, en la revista Lolapress. En: Debate Feminista. <en línea>, año 8, vol. 16, octubre de 1997, México. Disponible en la World Wide Web: <http://www.hartza.com/ butler.htm>

25 Butler, Judith. El género en disputa. Barcelona, España: Paidós, 2007, p. 47. 
ideal del patriarcado, y [...] las mujeres que el feminismo/los feminismos invocan son, quizá aquellas que han sido construidas por el discurso/los discursos feminista/s antes que una realidad mediata que sencillamente ha sido descubierta" 26.

En este sentido, es de vital relevancia definir bajo qué ámbito conceptual nos referiremos al concepto "sujeto", quiénes serán los sujetos del post-feminismo y, por ende, cuál es conceptualización que un sistema jurídico como el nuestro debería adoptar, a fin de cumplir con las pretensiones de libertad que se dan como presupuesto. Esta cuestión acerca de la "subjetividad" por lo tanto, contiene determinadas problemáticas, entendidas consecuencialmente como: primero, las condiciones de subjetividad ante la ley; segundo, el reconocimiento de aquellos sujetos que son invisibilizados; tercero, reconocimiento de los mecanismo sociales, científicos y, particularmente, jurídicos de disciplinamiento y constitución de los sujetos; y, por último, la modificación de esos mecanismos, enfocada a la satisfacción de la solución de los problemas mencionados supra.

\section{CRÍTICA AL CONCEPTO DE FAMILIA DESDE EL POST-FEMINISMO}

Para comprender la presencia de un indefinido concepto de familia, será necesario realizar el análisis de los sujetos que la ley reconoce como integrantes de dicha institución. No bastará, para desarrollar esta tarea, hacer un análisis conceptual intra-sistémico, sino la puntualización de los movimientos de resistencia ante el desconocimiento por parte del sistema jurídico, entendidas como luchas antiautoritarias producidas por la lógica conceptual imperante. La violencia corporal de la invisibilización es una huella que permite delimitar la defensa de un determinado concepto, y es eso importante porque de esa definición depende la relación entre la sociedad políticamente organizada y los sujetos individualmente considerados.

Cuando el Derecho tiene como objeto de análisis la relación prescriptiva entre los diversos sujetos de una sociedad humana, el acto de definición de quienes serán los sujetos que constituyan la sociedad, el problema se vuelca hacia las condiciones de lo humano. Si bien el tema de los límites de lo humano excede el presente trabajo, sí es pertinente señalar que un elemento de la tesis defendida es la ampliación de la subjetividad reconocida como legítima jurídicamente, destruir la predeterminación binarista de los sujetos (hombre-mujer) y proponer una solución a los problemas de reconocimiento y visibilización de los sujetos jurídicos.

Las teorías post-feministas, en particular la teoría queer, tienen como sustento teórico la obra de Michel Foucault, cuya problematización de las relaciones entre los sujetos y el poder es

26 Smart, Carol. La teoría feminista y el discurso jurídico. En: Birgin, Haydée (comp.). El Derecho en el Género y el Género en el Derecho. Buenos Aires, Argentina: Biblos, 2000, p. 42. 
de necesaria exposición. Entendiendo el poder en los términos de Foucault: "El poder no es una institución, no es una estructura ni una fuerza de la que dispondrían algunos: es el nombre que se le da a una situación estratégica compleja en una sociedad dada" 27.

La concepción de "poder" foucaulteana se aleja de las estructuras simbólicas tradicionalmente detentadoras de los mecanismos de ejecución del poder, ya no es el Estado el que ejerce coacción sobre los sujetos, pero tampoco deja de serlo: los agentes del poder se multiplican. El Estado sigue ejerciendo relaciones de poder con los demás sujetos, siendo una poderosa matriz individualizante. Sin embargo, el poder ejercido desde el gobierno estatal es una forma del poder, la cual se relaciona de manera horizontal con otras formas de poder, tales como el poder de las ciencias médicas, psiquiátricas, judiciales, penales, sexuales, familiares, etc. Surge desde estas instituciones la idea de un poder individualizante: "Esta forma de poder emerge en nuestra vida cotidiana, categoriza al individuo, lo marca por su propia individualidad, lo une a su propia identidad, le impone una ley de verdad que él tiene que reconocer y al mismo tiempo otros deben reconocer en él. Es una forma de poder que construye sujetos individuales"28.

El asunto de la constitución de los sujetos cobra gran relevancia. Precisamente este elemento es el que considera Butler cuando señala que existe un error en la base de las críticas feministas, consistente en que las estructuras de poder mismas son las que determinan las posibilidades de emancipación de los sujetos y a su vez los criterios de reconocimiento del sujeto como tal, o sea, que los medios lingüísticos sobre los cuales hablamos de "mujeres" son categorías que sirven como brazo al poder ${ }^{29}$.

Foucault, delimitó a lo largo de su obra la problematización que hizo del poder. Dos ideas aclaradoras pueden darnos pistas al respecto: "No concibo el poder en el sentido del gobierno o en el sentido del Estado. Me refiero a que entre personas diferentes, en una familia, en una universidad, en un cuartel, en un hospital, en una consulta médica, hay relaciones de poder"30, y tampoco "[...] quiere decir que el poder político esté en todas partes, sino que en las relaciones humanas se da todo un haz de relaciones de poder, que se pueden ejercer entre individuos, en el seno de una familia, en una relación pedagógica, o en el cuerpo político" 31 .

Con esto, la sexualidad se convierte en un campo de batalla, pues es revelado como mecanismo en el cual el poder está también presente. La conducta de los sujetos es determinada por los saberes asociados a las prácticas sexuales, y en concomitancia los sujetos son constituidos

27 Foucault, Michel. Historia de la sexualidad. La voluntad del saber. Buenos Aires, Argentina: Ediciones Siglo XXI editorial, 2002, vol. 1, p. 113.

28 Foucault, Michel. El sujeto y el poder. <en línea> 1983. Disponible en la World Wide Web: <http://www.philosophia.cl>

29 Butler, Judith, op cit. (n. 26), p. 48.

30 Foucault, Michel. "Sexualidad y poder". En su: Sexualidad y poder (y otros escritos). Barcelona, España: Ediciones Folio, 2007, p. 32.

31 Foucault, Michel. "La ética del cuidado de sí como práctica de la libertad". En su: Sexualidad y poder (y otros escritos). Barcelona, Espańa: Ediciones Folio, 2007, p. 57. 
mediante los mandatos conductuales que reciben desde las instituciones de dominación. En Foucault, el problema de la obediencia de los sujetos no es un problema ideológico como puede ser en la obra de Žizek, ni un problema de represión como puede ser en Marcuse, sino que, siguiendo a Deleuze: "Los dispositivos del poder no proceden ni por represión ni por ideología [...] En lugar de represión o ideología, [Foucault] formula un concepto de normalización y disciplina" 32 , y sigue, "los dispositivos de poder no se contentan sólo con ser normalizantes, tienden a ser constituyentes (de la sexualidad)"33.

Las relaciones de poder, en este sentido, tienden a la normalización de los sujetos. Lo que en términos sexuales patriarcales se traduce en hacer concordar lo que el sujeto debe ser según lo que su bio-fisiología indica que debería ser con lo que está siendo. En otras palabras, que quienes tengan genitales masculinos sean hombres y deseen como hombres, mientras que quienes tengan genitales femeninos sean mujeres y disfruten de los placeres asignados simbólicamente a las mujeres. Quien no está dentro de la norma, necesariamente, es porque está fuera de la norma, lo que se traduce en su anomalía: quien no está dentro es un anormal. Los anormales, en este sentido, son los sujetos sin subjetividad, ya que no son reconocidos sino por su desconocimiento. El anormal existe en tanto sirva para definir al sujeto principal, similar al concepto de alteridad en Simone de Beauvoir, el cual entiende a la mujer como "la otra" complementaria del hombre, siendo diferente en este caso porque se cuestiona la subjetividad misma del sujeto principal: ¿qué es lo normal?, ¿existe realmente un "hombre" independiente de una "mujer"?, ¿existe lo "normal" con independencia de lo "anormal"?

En este sentido, podemos decir que existen estándares normativos-prescriptivos que determinan el deber ser de la existencia de determinadas relaciones de poder, de las cuales el sujeto que no es parte de ellas está fuera de la sociedad: la familia, en nuestra sociedad, tiene como fundamento el matrimonio, delimitándose así lo social a lo matrimonial. Y más precisamente, lo matrimonial está en directa relación con una determinada función "social": la reproducción. Acotados los términos, podemos decir que quien no cumpla con la función reproductiva, útil para la sociedad, está fuera de ésta. Se ocupa un elemento contingente producido dentro de las relaciones familiares como elemento único de delimitación de lo que puede ser considerado como parte de la sociedad y lo que no, definiendo de paso de manera tristemente funcionalista la sociedad al darle un fin meramente de reproducción.

El dejar de lado otras características de las relaciones sociales sobre las cuales se puede constituir algo así como una "familia" es esencializar a los sujetos de la forma más amplia posible, ya que de la misma manera que un perro que no ladra es un perro que no funciona, un ser humano que no se reproduce sería un ser humano que no sirve. Se esencializa de modo tal que lo humano está definido por lo útil, sin considerar a este un beneficiario directo de la sociedad.

32 Deleuze, Gilles. Deseo y placer. Córdoba, Argentina: Alción Editora, 2004, p. 16.
33 Ibid. p. 17. 
El primer problema de este razonamiento radica en la no consideración de una serie de elementos que pueden de igual manera determinar lo familiar, sin excluir el elemento reproductivo, a saber: el amor, el mantenimiento de una propiedad en común, el mantenimiento de valores sociales, etc. Todos estos elementos son aplastados por el afán reproductivo considerado como esencial de los seres humanos.

Un segundo problema es una falacia non sequitur, en términos tales que de las prácticas de los sujetos no se sigue su esencia. En sentido jurídico, el "hombre" y la "mujer" son definidos en base a un discurso científico determinado, por lo que se esencializa en base a ciertos elementos de su cuerpo, pero también se asignan a esos sujetos una serie de conductas aceptadas sobre las cuales puede desarrollarse "correctamente". Por otra parte, los sujetos que no cumplen con esas determinadas prácticas conductuales son categorizados de forma distinta, ya no dentro de los parámetros de normalidad, sino fuera de ellos. Las prácticas "subversivas" o "anti-normativas" de los sujetos lo determinan como un excluido, invisibilizándolo ¿Es correctamente predicada, por ejemplo, la homosexualidad de un hombre que fue sorprendido en la cama con otro hombre?, ¿se puede decir de un sujeto con cuerpo masculino que se viste con ropa femenina que es un "travesti"? La resolución de estas preguntas es fundamental para nuestro sistema jurídico, cuando la homosexualidad es causal de divorcio y el travestismo atentaría contra "las buenas costumbres". Ante ello podemos elucidar una respuesta, aunque el debate profundo quedará disponible para otra instancia: las prácticas de los sujetos deben ser entendidas como manifestaciones de su deseo de ser-reconocido dentro de un determinado conjunto de prácticas, así los símbolos materiales que transportan los sujetos (vestimentas y accesorios, determinada utilización del lenguaje, conductas, opiniones, placeres, etc.) son determinantes de su deseo interno ante los demás. Por ello, los elementos exteriores mediante los cuales el sujeto comunica su subjetividad al mundo, son una serie de actos performativos que determinan al sujeto a través del mero acto de ser reconocidos como tales por los demás, es decir, un hombre será reconocido como tal mientras realice un conjunto de actos sobre los cuales se pueda inferir su deseo de "ser hombre", lo mismo ocurre con una mujer; radicando el problema en las prácticas contraindicadas: del acto particular contraindicado no se sigue la anti-normatividad de la totalidad del sujeto. Sin embargo tal categorización del sujeto como elemento social de anormalidad se entiende como manifestación del poder, en tanto mecanismo normalizador: para poder normalizar debe existir el anormal. El acto anormal, por lo tanto, da existencia real al poder.

Por último, cabe mencionar que la extensión recién mencionada de las prácticas debe ser aplicada también al concepto de familia. Lo familiar es determinado mediante el mero acto solemne del matrimonio, jurídicamente hablando, acto del cual no se sigue siquiera que se dé por cumplida la finalidad de lo familiar, entendido como la reproducción de la especie. El desconocimiento intencional, por una parte, de las diversas formas mediante las cuales se puede hablar de relaciones familiares, y el entendimiento, por otra parte, del sexo como medio de una 
única función social aceptada, la reproducción, dan lugar a una concepción de lo social completamente ciega en relación con las prácticas de los sujetos individualmente considerados. Así, el diálogo entre los sujetos y el Estado no es exitoso.

Por lo tanto, un concepto de familia informado y conciente de las relaciones sociales existentes debiera, como primer y básico elemento, dar solución a las problemáticas planteadas: redefinir la finalidad de la existencia de lo familiar; reinterpretar de manera múltiple las condiciones en que un sujeto puede participar de lo familiar; y, reconocer el disfrute de los placeres sexuales por parte de los sujetos, sin asignarle una carga axiológica negativa necesaria por no aportar a la reproducción humana.

De todas maneras, para enfrentar y asumir esta crítica es necesario estar abierto a las posibilidades reinterpretativas del concepto "familia", e incluso a la negación conciente del concepto mismo. Tal negación o reestructuración del concepto "familia" tiene asidero en la posibilidad de ampliar el espectro de relaciones sociales que nos permitan referir lo familiar y determinar qué es aquello que mantiene unidos a los sujetos, no individualmente considerados, sino como miembros de una familia. Judith Butler, al respecto establece una diferencia determinante en relación con el concepto familia: "familia" no es lo mismo que "parentesco":

'Creo que tenemos que distinguir familia' de 'parentesco', pensando parentesco como ese grupo de personas de las que dependemos y que dependen de nosotros, una comunidad que participa de las mayores celebraciones y pérdidas de nuestras vidas. Creo que es un error restringir la idea de parentesco a la familia nuclear. Creo que todos necesitamos producir y sostener este tipo de comunidades. Demasiado peso emocional se deposita sobre la familia y la pareja, y encima estas instituciones deben abrirse a mundos más amplios. No es necesario estar unidos por la sangre o por el matrimonio para convertirse en esenciales unos para los otros. No solamente tenemos que imaginarnos más allá de estas maneras de relacionarnos sino también cómo podriamos vivir en ellas"34.

El discurso que sostiene una igualación conceptual entre "familia" y "parentesco" sostiene un orden estrictamente heterosexual (y heterosexualizante) de la sociedad, debido a que el matrimonio y la reproducción son elementos necesarios para constituir estas relaciones. Así, las instituciones jurídicas centrales que determinan las relaciones sociales-familiares son determinadas de antemano como heterosexuales. Desde lo teórico se regula la existencia de prácticas realizadas por los sujetos, limitando su derecho de reconocimiento por parte de un sistema jurídico que tiene pretensión de ser pluralista y/porque democrático.

34 Michalik, Regina. op cit. (n. 24). 


\section{EXCURSO: EL PROBLEMA DE LA RESISTENCIA}

El feminismo liberal funda sus premisas en el progreso de la humanidad, según la relación revisada desde Mill que promueve el principio de utilidad desde la perspectiva social de la mayor utilidad para el mayor número; el post-feminismo, en cambio, rechaza la idea de un progreso o una racionalidad generales, optando por racionalidades específicas ${ }^{35}$, en función de un modo crítico basado en la post-modernidad. Desde el post-feminismo el quid del asunto no es la universalización de la utilidad producida por la igualdad formal, e incluso material, entre hombres y mujeres, sino que muy distante de eso el tema es por el cuestionamiento mismo de las categorías sobre las cuales son constituidos los sujetos. En ese sentido la crítica hacia un concepto de familia como el presente en nuestro sistema jurídico puede realizarse de dos maneras que lo comprendan: por un lado, la crítica clásica desde el feminismo liberal puede ser entendida como una crítica intrasistémica, en tanto que los conceptos que intentan ser reformulados y las situaciones que intentan ser reivindicadas presentan una equivalencia argumentativa con la lógica que resiste dicha reivindicación. Son lenguajes que se reconocen y se contraargumentan de modo tal que se presentan las razones sobre las cuales cabría adoptar como propia una determinada conducta, en este caso conducta jurídica. Por otro lado, la crítica del post-feminismo combate en primer lugar contra la meta-argumentación presente en el discurso contrario, reformulando las nociones mismas sobre las cuales se pueden sentar las premisas argumentativas relativas al problema del género.

Desde la perspectiva de la segunda crítica, la post-feminista, el combate es contra nosotros mismos, puesto que la destrucción de los conceptos dados e imperantes es la destrucción de los sujetos y sus relaciones sociales, las cuales incluyen epistemológicamente la argumentación en su contra. Hegelianamente, quien argumenta debe renunciar a su ser-reconocido a fin de tener la posibilidad de desarmar el aparataje que lo constituye de una determinada manera. La pregunta, en este sentido se convierte en la cuestión sobre la normalización, pero no desde un punto de vista explicativo (¿qué es aquellos que determina que los sujetos ejecuten determinadas prácticas que los hacen estar dentro de la "normalidad"?), sino desde el concepto de libertad: ¿cómo es posible la resistencia a la normalización? Tal pregunta se conforma como un motor ético de las relaciones sociales, por lo tanto responder esta pregunta es fundamental para el éxito político de las ideas del feminismo o de la teoría queer, ya que desde esa respuesta deben ser estructuradas las políticas y actividades de los movimientos políticos y sociales que las tienen como fundamento. En relación con esta idea de posibilidad de la libertad de los sujetos, Foucault señala que: "La conclusión podría ser que el problema político, ético, social y filosófico de nuestros días no es tratar de liberar al individuo del Estado y de las instituciones del Estado sino

35 Foucault, Michel, El sujeto... (n. 28), p. 5. 
liberarnos de ambas, del Estado y del tipo de individualización que está ligada a éste. Debemos promover nuevas formas de subjetividad a través del rechazo de este tipo de individualidad que nos ha sido impuesta durante siglos" 36 .

La construcción de los paradigmas de subjetivización está atravesada por una resistencia, como Foucault describe. Revestida de los discursos del poder científico, la sociedad patriarcalcapitalista (sociedad disciplinaria, en términos de Foucault) define a los sujetos a partir de una determinación biológica que, además de favorecer al segmento "masculino" de la sociedad, evita cualquier referencia a lo cultural. Es así como se patrocina una serie de prácticas que moldean y constituyen a los sujetos, prácticas que van desde las reacciones emocionales aceptadas por la comunidad hasta la ropa u otros simbolismos exteriores que cada sujeto utilizará, en algún sentido, para identificarse como parte de lo masculino o de lo femenino, lo normal. Para evidenciar la arbitrariedad de tales proposiciones, es necesario presentar la división conceptual básica entre sexo y género:

"Género: la construcción cultural de las características biofisiológicas percibidas, es decir, la designación sociocultural de las características comportamentales y psicosociales de los sexos.

Sexo: se refiere a las características biofisiológicas de los individuos: machos, hembras, hermafroditas, andróginos o personas intersexuales" 37.

Mientras el sexo es una "condición natural" de los sujetos, proveniente de la naturaleza misma y explicada por la ciencia, el concepto de género puede definirse como el conjunto de creencias, rasgos personales, actitudes, sentimientos, valores, conductas y actividades que diferencian a hombres y mujeres a través de un proceso de construcción social, caracterizado principalmente por ser un proceso histórico y por ser jerarquizado, en tanto tiene más valor la figura masculina que la femenina.

Es por ello que, si bien la conceptualización de los sujetos en torno a su género y no su sexo fue un avance en lo que a teoría feminista se refiere, hoy desde el post-feminismo se advierte que es una manera más de establecer el dualismo patriarcal, ya que si antes se estimaba que se era hombre o mujer por tener un genitales masculinos o femeninos, ahora el criterio se corresponde con si el sujeto se viste de azul o de rosado, si juega con muñecas o con autitos, si es médico o enfermera, si es cesante o "dueña de casa".

Hasta aquí, lo entendido por sociedad patriarcal construye entidades "normales", como sociedad disciplinaria es normalizante: hay hombres y mujeres, y los hombres valen más. A fin de elucidar un posible escape de la dominación, me valdré del argumento de Judith Butler: “[El

36 Foucault, Michel. Sexualidad... (n. 31), p. 12.

37 Beltrán, Elena y Maquieira, Virginia (eds.). “Género, diferencia y desigualdad”. En su: Feminismos. Debates teóricos contemporáneos. Madrid, España: Alianza editorial, 2000, p. 181. 
género] al ser producido discursivamente desde prácticas de exclusión, la lucha contra el género requiere la inclusión de todos los discursos posibles sobre el sexo, las prácticas sexuales y las identidades sexuales, de modo que se genere así una proliferación de géneros que constituyen juegos irónicos, parodias estilísticas que tienen como objetivo desestabilizar el género"38.

El llamado es a destruir el género, a través de la anulación del concepto por sobrecarga: al no poder explicar la realidad, el género como noción se vuelve inútil. Esta destrucción, ¿es una posibilidad de emancipación de los sujetos del entramado normalizador de la sociedad patriarcal? El panorama de lo patriarcal, primero, podemos presentarlo de acuerdo con las siguientes ideas:

a) El sistema patriarcal establece un estándar de lo masculino y lo femenino: ciertos elementos accesorios al sujeto lo determinan como hombre o como mujer según sea el caso (vestimenta, gustos, actitudes emocionales, léxico, tono de voz, etc.).

b) La constitución del sujeto se produce de modo discursivo a través del mensaje del género: bajo el supuesto de la existencia de una dualidad, se llama a los sujetos a reconocerse como parte de aquel rol que están tomando en la sociedad, en términos de saberse hombre o mujer y actuar de acuerdo a ello.

c) Quien no se ajusta al género que, biológicamente, le corresponde, no será reconocido como sujeto, calificándosele como un anormal y por lo tanto siendo marginado de la sociedad: la marginación de los sujetos es un proceso histórico que va desde los dementes y los delincuentes hasta las mujeres, los travestis, los transgénero, los vagos y las prostitu$\operatorname{tas}^{39}$.

Bajo los fundamentos propuestos, cabría decir que el reconocimiento auto-consciente del sujeto es la condición de posibilidad de libertad, en el sentido deconstructivo del género, en tanto el individuo puede elegir constituirse como un sujeto distinto del que se le conmina a ser. Parece presentarse una situación de resistencia posible de la normalización en la posibilidad de destrucción de las categorías mismas de género, siendo estas destacadas por aquellos anormales relacionados directamente con "anomalías" sexuales. Al respecto, me permito la excentricidad de un ejemplo: 'Hija de Perra'.

'Hija de Perra' es una actriz y cantante travesti chilena. Protagonista del flm independiente "Empaná de pino" (2008), ofrece de vez en cuando sus "performances" en universidades o en clubs queer, under y alternativos, dada a los excesos de todo tipo, no le importa mostrar sus genitales en público, ni tener relaciones sexuales, penetraciones con prótesis, beber orina, comer excremento, jugar con semen, todo en vivo ante las miradas más excitadas que sorprendidas

\footnotetext{
38 Butler, Judith. op cit. (n. 25), p. 56.

39 Cf. Foucault, Michel. Los anormales. México: Fondo de Cultura Económica, 2004.
} 
de sus espectadores: lo que ella quiere, dice, es "divertir y traumar" a la gente. 'Hija de Perra', podríamos decir, destruye el género: se besa con hombres y mujeres, con lesbianas y homosexuales, incluso con animales; tiene una estética evidentemente femenina, sin embargo bajo un análisis patriarcal, podemos evidenciar de inmediato sus rasgos bio-fisiológicos masculinos; no tiene pene, pero lo simula con dildos de variados colores y tamaños; las letras de sus canciones llaman a la promiscuidad y al sin-sentido: está claro, ella no respeta los parámetros establecidos para su condición sexual-bio-fisiológica.

¿Constituyen "actos de resistencia” la actitud de 'Hija de Perra'? Podemos dar argumentos para dos respuestas posibles: Primero, sí. Ir en contra de los discursos que se establecen para los sujetos determinados es una manera de deconstruir el mensaje interpelativo y convertirlo en un contra-discurso llamativo que debilita el disciplinamiento. Esta manera de abordar lo normalizador, nos lleva a un choque de "normalidades": el combate de la normalidad se inicia con la estructuración de una normalidad alternativa, lo que es decir que se extiende el parámetro de lo que es parte del conjunto de lo normal. Esta posición en la que es posible convertir lo anormal en normal, lo entiendo como una acto performativo de negación de la configuración original para dar lugar a una nueva realidad; la negación de la subjetividad con el fin de abrir una serie de subjetividades posibles.

Bajo ese sentido, no habría una resistencia propiamente tal por parte de los sujetos, en tanto sólo podrían trasladar y validar su agencia desde una "normalidad" a otra distinta, pero distinta sólo porque más amplia. Este análisis, incluso, abre la puerta a la crítica bajo la cual se presenta como consciente por parte de las instituciones normalizadoras imperantes de construir ciertos sujetos que se presenten como extrasistémicos, que permitan entender la normalidad desde lo no-normal: el ethos bajo el cual se constituye 'Hija de Perra', lejos de ser aceptado por la sociedad, se presenta como ejemplo del "mal ético" sobre el cual los sujetos deben discriminar: el mensaje es a no elegir la opción de ser como 'Hija de Perra', precisamente porque usted individuo será un marginado como ella.

Segundo, no. El sujeto se entiende resistiendo cuando contradice el discurso normalizador, sin embargo es eso precisamente lo que fortalece al discurso: Es necesario suponer una determinada posibilidad previa de libertad en, por ejemplo, 'Hija de Perra'; es un objetivo de esa misma resistencia, con base en la libertad, la que persigue alcanzar la libertad, pareciendo que existe una ilusión de alguna de las libertades: o la libertad que se busca ya se tenía cuando se resistía la normalización; o bien, la base sobre la cual se resiste no es libre y es un elemento de la misma normalización, es una rama del poder. Donde hay poder, hay resistencia, diría Focault.

Podemos considerar que la situación de constitución del sujeto desde la alteridad negativa del discurso disciplinario hegemónico, convierte al sujeto que se está constituyendo en un emisor dependiente del sistema de símbolos dados, a fin de constituirse de modo performativo desde su agencia como un reconocible opositor al sistema de elementos característicos de un sujeto "bien constituido". Este es mi punto: 'Hija de Perra' sólo será entendida como resistencia o 
contradictora dentro de este sistema lingüístico y no otro, pues es sólo de esta manera que logra formarse como "distinta", precisamente porque es distinta en comparación con un paradigma discursivo establecido.

En Foucault existe como premisa la posibilidad de libertad del individuo, por el contrario a lo que piensan algunos autores, que incluso consideran que este es precisamente el punto más débil de la teoría foucaulteana ${ }^{40}$. Es de esta manera por medio de la cual se consigue evadir la observación del panóptico descrito ya en "Vigilar y castigar", llegando a existir una posibilidad de desobediencia, en cuanto resistencia, como condición de la liberación del sujeto de la negación del ejercicio de la libertad. Cabe agregar que el concepto de libertad que entiendo, siguiendo una lectura de Foucault, está en estrecha relación con el concepto de poder como relación compleja dentro de una sociedad liberal. Así, cuando Foucault dice que el poder está en todas parte "se está refiriendo más bien a lo que podríamos llamar poder liberal, es decir, a la clase de poder que funciona en el estado liberal moderno, el cual toma como objetos a los 'sujetos libres' y se define completamente en relación con ellos y su libertad [...] El poder liberal no se contenta simplemente con prohibir, ni aterrorizar directamente, sino que normaliza, 'responsabiliza’ y disciplina" ${ }^{41}$. El liberalismo entrega más posibilidades de elección de la sexualidad, sin embargo tras la elección aparecen responsabilidades indelegables determinadas por las conductas "normales" sobre las cuales el sujeto debe comportarse.

Sobre lo anterior, el sujeto tiene la posibilidad de elección a cada instante de su actuar, superar el miedo proveniente de los dispositivos de poder que coaccionan la conducta y desarrollar actos de resistencia que den forma a la libertad no liberal: la libertad está en la posibilidad de ponerse en un espacio de inclasificación. Los seres humanos son infinitos, sus posibilidades no están inherentemente disciplinadas, existe un espacio de libertad precisamente en el momento de cada elección. El reproche proviene tras la mala elección, pero esa libertad con la que el ser humano cuenta consiste en elegir precisamente que el reproche no sea exitoso sobre él.

Volviendo al mito de Procusto, podemos descansar sobre una cama que nos quede corta, como también podemos hacerlo sobre una que nos quede larga, pero aún más: podemos haber ido a una enciclopedia, haber leído el mito de Procusto y no aceptar su invitación.

Lo que queda en relación con las tesis sobre lo familiar, en definitiva, es comprender que la postura que tiene el sistema liberal en consonancia con sus mismos postulados no es coherente. Sobre eso se presentan maneras de entender, pero no soluciones: lo importante es que esto es un problema y no un estado de cosas naturales.

40 Cf. ŽızeK, Slavoj. "El espectro de la ideología”. En su: ŽIzeK, Slavoj (comp.). Ideología: un mapa de la cuestión. México: Fondo de Cultura Económica, 2003, pp. 7 - 42.

41 Halperin, David. San Foucault. Para una hagiografía gay. Córdoba, Argentina: El cuenco de plata, 2007, pp. 36 - 37. 


\section{REFERENCIAS BIBLIOGRÁFICAS}

Beltrán, Elena y Maquieira, Virginia (eds.). “Género, diferencia y desigualdad”. En su: Feminismos. Debates teóricos contemporáneos. Madrid, España: Alianza editorial, 2000.

ButLer, Judith. El género en disputa. Barcelona, España: Paidós, 2007.

Caviglia, María Jorgelina. "Discurso y naturaleza femenina: ideología sexista en la Inglaterra victoriana”. En: Actas del III coloquio nacional de investigadores en estudios del discurso. Buenos Aires, Argentina, 2006.

Deleuze, Gilles. Deseo y placer. Córdoba, Argentina: Alción Editora, 2004.

De Miguel, Ana. "El feminismo en clave utilitarista ilustrada: John S. Mill y Harriet Taylor Mill”. En su: Amorós, Celia y De Miguel, Ana (eds.). Teoría feminista: de la ilustración a la globalización. Madrid, Espańa: Ediciones Minerva, 2005.

Foucault, Michel. Historia de la sexualidad. La voluntad del saber. Buenos Aires, Argentina: Ediciones Siglo XXI editorial, 2002, vol. 1. El sujeto y el poder. <En línea> 1983. Disponible en la World Wide Web: <http://www.philosophia.cl>. "Sexualidad y poder". En su: Sexualidad y poder (y otros escritos). Barcelona, España: Ediciones Folio, 2007.

"La ética del cuidado de sí como práctica de la libertad". En su: Sexualidad y poder (y otros escritos). Barcelona, España: Ediciones Folio, 2007.

Halperin, David. San Foucault. Para una hagiografía gay. Córdoba, Argentina: El cuenco de plata, 2007.

MılL, John Stuart. El utilitarismo. Madrid, España: Alianza editorial, 2007.

Sobre la libertad. Madrid, España: EDAF, 2007.

"La sujeción de las mujeres". En su: Mill, John Stuart y TAYlor Mill, Harriet. Ensayos sobre la igualdad sexual. Valencia, España: Ediciones Cátedra, Universitat de Valencia, 2001.

MichaLıк, Regina. "La invención de la palabra”, entrevista realizada a Judith Butler, en la revista Lolapress. En: Debate Feminista. <en línea>, año 8, vol. 16, octubre de 1997, México. Disponible en la World Wide Web: $<$ http://www.hartza.com/butler.htm>

Smart, Carol. La teoría feminista y el discurso jurídico. En: Birgin, Haydée (comp.). El Derecho en el Género y el Género en el Derecho. Buenos Aires, Argentina: Biblos, 2000.

Urmson, James Opie. Interpretación De la filosofía moral de J. S. Mill. En: Foot, Philippa, Teorías sobre la ética. México, D. F.: Fondo de Cultura Económica, 1974, pp. 188 - 199. 